EDITORIAL

\title{
Antiretroviral Therapy Program in Ethiopia Benefits From Virology Treatment Monitoring
}

\author{
GebreAb Barnabas ${ }^{1}$, Manuel K. Sibhatu ${ }^{2}$; Yemane Berhane ${ }^{3}$
}

\author{
OPEN ACCESS \\ Citation: GebreAb Bernabas, Manuel K. \\ Sibhatu, Yemane Berhanel. Antiretroviral \\ Therapy Program in Ethiopia Benefits \\ From Virology Treatment Monitoring \\ . Ethiop J Health Sci 2017;27(si1):1-2. \\ doi: \\ http://dx.doi.org/10.4314/ejhs.v27i1.1S \\ Received: February 1, 2016 \\ Accepted: August 12, 2016 \\ Published: March 15, 2017 \\ Copyright: GebreAb B et al. This is an \\ open access article distributed under the \\ terms of the Creative Commons \\ Attribution License, which permits \\ unrestricted use, distribution, and \\ reproduction in any medium, provided the \\ original author and source are credited. \\ Funding:Center for Disease Control and \\ Prevention (CDC) \\ Competing Interests: The authors \\ declare that this manuscript was approved \\ by all authors in its form and that no \\ competing interest exists. \\ Affilation and Correspondence: \\ ${ }^{1}$ Tulane Interneational/Ethiopia \\ ${ }^{2}$ Food, Medicine and Health Care \\ Administration and Control Agency of \\ Ethiopia \\ ${ }^{3}$ Addis Continental Institute of Public \\ Health \\ *GebreAb Bernabas, E-mail: \\ gebreab2002@gmail.com
}

Introduction of combination ART was instrumental to mitigate the burden of HIV pandemic in Ethiopia and other resource limited settings. Combination ART archives sustained HIV viral suppression and contributes to reductions in mortality, progression to AIDS, opportunistic infections (OIs), and hospitalization (1). Viral suppression is also associated with decreased HIV transmission to uninfected persons. In Ethiopia, improved coverage of free antiretroviral therapy (ART) program helped to enroll hundreds of thousands of ART needy people living with HIV; an overall ART coverage reached $73 \%(2-3)$.

Failure of antiretroviral treatment and toxicity are feared complication of long-term ART users. Noncompliance to medical instruction and poor adherence fosters emergence of drug resistant mutant. An observational cohort study from HIV clinic in South Africa which enrolled 19,645 patients $(29,935$ person-years) showed that $9.9 \%$ of first line ART $(4.5 / 100$ person-years) failed at median 16 (IQR: 12-23) months following ART initiation. Five years following ART treatment, the failure rate was $16.9 \%$ and $7.8 \%$ when using a confirmatory threshold of 400 and 10,000 copies $/ \mathrm{ml}$, respectively. The same study reported a $10.1 \%$ overall rate of switch to second-line by five years on ART (4). The emergence of primary and secondary HIV drug resistance is on the rise due to accumulation of mutant HIV strains and weak error proof reading capability of the virus. A systematic review of studies on prevalence of HIV-1 drug resistance in treatment-naïve individuals in resource-limited settings since roll out of ART programs, showed the highest estimated rate of increase at $29 \%$ per year (95\% CI 15 to 45; $\mathrm{p}=0.0001)$ in East Africa; an estimated prevalence of HIV-1 drug resistance at eight years after ART program is $7.4 \%$ (5). Moreover, there is an increase incidence of resistance to non-nucleoside reverse transcriptase inhibitors in East Africa (36\% per year; $\mathrm{p}<0.0001)$ and Southern Africa (23\% per year; $\mathrm{p}=0 \cdot 0049$ ). Among the subset of studies reporting treatment failure with HIV-specific resistance mutation data (27 studies with 734 patients), the most common mutations were the M184V mutation, found in $65 \%$ of patients, and the $\mathrm{K} 103 \mathrm{~N}$ mutation, found in $52 \%$ of patients (5-6).

The clinical and epidemiological implications of drug toxicity and treatment failure from HIV drug resistance are huge. In addition to mortality and morbidity, the increased transmission of HIV resistant virus to intimate sex partners and increased health care cost will be enormous. At individual patient level, failed ART regimen or HIV drug resistance limits treatment options,complicates succession of therapy and puts the patient at increased risk for drug toxicity from second-line regiments who may need close vigilance and laboratory monitoring. In addition, limited availability 
of laboratory services such as drug toxicity screening, HIV virology and drug resistance testing monitoring may contribute to delay in diagnosis of treatment failure in resource limited setting where virology monitoring is not a component of routine ART monitoring (6-8).

The World Health Organization (WHO) recommends viral load determination, if feasible, to improve the identification of treatment failure. Due to financial and logistical constraints in resource limited settings, however, access to this expensive and technically demanding test is limited. Therefore, as a substitute, WHO-recommended clinical criteria and CD4 cell counts are commonly used by clinicians to diagnose ART failure and guide treatment switch (9). In the absence of viral load monitoring, unnecessary regimen switches are common, resulting in increased treatment costs and loss of future options for treatment succession. Also, late detection of treatment failure results in high frequencies of accumulated mutations conferring broad cross-resistance to NRTIs, which may impair the

It is vital to understand factors that determine success of ART and treatment follow up for such evidence informs program monitoring, quality and safety of HIV prevention, treatment and care services in Ethiopia.

In this special edition of the EJHS, the authors present readers insightful articles on antiretroviral therapy program in Ethiopia with emphasis on antiretroviral therapy monitoring and lessons learnt from the ACM cohort of HIV positive individuals enrolled to ART program in seven university hospitals at higher education institutions across Ethiopia.

It is very much hoped that esteemed readers will read through the articles in this edition. It is also believed that the evidences and lessons learnt from these articles will encourage further research, incite scientific debate on treatment monitoring and inform national guidelines on HIV/ART program monitoring.

\section{REFERENCES}

1. Assefa Y, Kiflie A, Tesfaye D, Haile-Mariam D, Kloos H, Edwin W, et al. Outcomes of antiretroviral treatment program in Ethiopia: Retention of patients in care is a major challenge and varies across health facilities.BMC Health Services Research 2011, 11:81.

2. Federal Democratic Republic of Ethiopia. 2011 Ethiopian Demographic and Health Survey $(E D H S)$. Addis Ababa: Central Statistical Agency; 2012.
3. Federal Ministry of Health of Ethiopia. Annual Performance Report of Health Sector Development Programme IV (HSDP IV), Report number: EFY 2005 (2012-13). Addis Ababa; 2013.

4. Fox MP, Cutsem GV, Giddy J, Maskew M, Keiser $\mathrm{O}$, Prozesky $\mathrm{H}$, et al. Rates and predictors of failure of first-line antiretroviral therapy and switch to second-line ART in South Africa. $J$ Acquir Immune DeficSyndr 2012; Aug $1 ; 60(4): 428-37$. doi: 10.1097/QAI.0b013e3182557785.

5. Gupta RK, Jordan MR, Sultan BJ, Hill A, Davis DHJ, Gregson J, et al. Global trends in antiretroviral resistance in treatment-naive individuals with HIV after rollout of antiretroviral treatment in resource-limited settings: a global collaborative study and meta-regression analysis. Lancet 2012; 380: 1250-58

6. Hosseinipour MC, Gupta RK, Van Zyl G, Eron JJ, Nachega JB. Emergence of HIV drug resistance during first- and second-line antiretroviral therapy in resource-limited settings. J Infect Dis. 2013 Jun 15;207Suppl 2:S49-56. doi: 10.1093/infdis/jit107.

7. Barth RE ,Loeff MFS, Schuurman R, Hoepelman AIM , Wensing AMJ. Virological follow-up of adult patients in antiretroviral treatment programmes in sub-Saharan Africa: a systematic review. Lancet Infect Dis 2010; 10: 155-66

8. Khienprasit N, Chaiwarith R, Sirisanthana T, Supparatpinyo K. Incidence and risk factors of antiretroviral treatment failure in treatment-naïve HIV-infected patients at Chiang Mai University Hospital, Thailand. AIDS Research and Therapy 2011 8:42. doi:10.1186/1742-6405-8-42

9. World Health Organization. HIV Drug Resistance Early Warning Indicators: Indicators to monitor HIV drug resistance prevention at antiretroviral treatment sites. April 2010. Available from the WHO HIV Drug Resistance web site: http://www.who.int/hiv/drugresistance.

10. Federal Ministry of Health. Guidelines for Management of Opportunistic Infections and AntiRetroviral Treatment in Adolescents and Adults in Ethiopia. Federal HIV/AIDS Prevention and Control Office, Addis Ababa; March 2008.

11. Boyer S, March L, Kouanfack C, Laborde-Balen G, Marino P, Aghokeng AF, et al. Monitoring of HIV viral load, CD4 cell count, and clinical assessment versus clinical monitoring alone for antiretroviral therapy in low-resource settings (Stratall ANRS 12110/ESTHER): a costeffectiveness analysis. Lancet Infect Dis 2013; 13: $577-86$.

DOI: http://dx.doi.org/10.4314/ejhs.v27i1.1S 